\title{
The category of the heart in philosophy and religion: from mysticism to pragmatics
}

\author{
Nikolay Rybakov ${ }^{1 *}$ \\ ${ }^{1}$ Pskov State University, 2, Lenin Place, Pskov, 180000, Russia
}

\begin{abstract}
One of the extremely urgent problems of modern anthropology is the problem of the whole person, more precisely, the problem of the completeness of his nature. It includes many elements of a different nature, which raises the question of the existence of a center that controls human activity as an integral being. The author proceeds from the fact that such a coordinating center, in accordance with historical, philosophical and religious studies, is the human heart. The article analyzes the features of understanding the heart, presented in the philosophical and religious literature. Special attention is paid to the views of the Christian philosopher A. S. Pozov, who takes a clear position in revealing the fundamental role of the human heart in all the diversity of its existence. The functional elements of cardiac activity, which can be of practical importance, have been identified. A series of questions about the practical applications of heart problem research has been formulated. This is the role and significance of the heart in the transition to a digital society. These are, further, the ways and means of transformation of human nature and their justification. Finally, following I. A. Ilyin, we talk about the need to study the evolution of the forms of "heart contemplation."
\end{abstract}

\section{Introduction}

In philosophical and religious anthropology, the nature of man, his multi-composition is discussed in detail, efforts are made to reveal the essence of man, the evolution of man, his ages, the meaning of life, death and immortality are investigated. And, perhaps, no matter what side of a person's being touched, it is found everywhere that there are much more unsolved problems than clarified and finally closed ones.

One of these - quite intensively discussed, but remains almost elusive - is the problem of the whole person (integrity, wholeness, etc.). It is quite obvious that many different elements are included in the composition of human nature, the problem of the plurality of "I" is intensively considered in the literature and becomes the subject of fashion, especially if we turn to a person immersed in numerous diverse empirical situations that are hardly amenable to any or classification. At the same time, if these elements are not held in any way by any

\footnotetext{
*Corresponding author: malkogospel@,mail.ru
} 
force, are not connected with each other in any way, then it will not be possible to detect a person in any of his projections. We deliberately allowed the following line of thought: let a person be a multiple, many-sided being, and every time he reveals himself to the world in some way. But if he is just like that - multiple, then his manifestation in the world in a certain way (the "image" of a person is his projection into the local world) is carried out in the form of a kind of coherence, singularity: a person is multitude, but each of his images in the world is something a single, tied in a tight knot, where its various elements somehow "manage" to come together to show a person to the world in a certain way. And let there be a great variety of these very images, but each image, composed of a number of elements, turns out to be a kind of integral picture in which these elements are interconnected. This is where a rather complicated problem of the integrity of a person arises, the presence of a single-separate structure in which much is compositionally linked into what we call a person. Note, we call one general concept "person", and do not use, say, for each state of a person a separate independent word. By the way, some peoples of the North do not have a common concept of "snow", but there are words to designate its various states.

At the intersection of these problems, the questions arise: what and how makes a person an integral being? And, in general, is it possible and is there a whole person? Let us turn to study them to the three-component nature of man, which is widely discussed in different religions.

\section{Materials and methods}

Body, soul and spirit, which form the trinity of man, are diverse principles. Man, however, is a single, integral being. Note that for a theoretical formulation of the question of the wholeness of a person, the intuition of a "whole person" must first "hover" in research, otherwise the very formulation of the question will look like a miracle. In order to unite heterogeneous parts into a whole, an organ must exist in human nature as a unifying and guiding principle, as a center of spiritual-mental-bodily unity. Such an organ, according to the teachings of ancient church anthropology, in a human being is the heart, which itself must be at the same time a spiritual, mental and bodily organ, or, in other words, the focus of the spirit, soul and body.

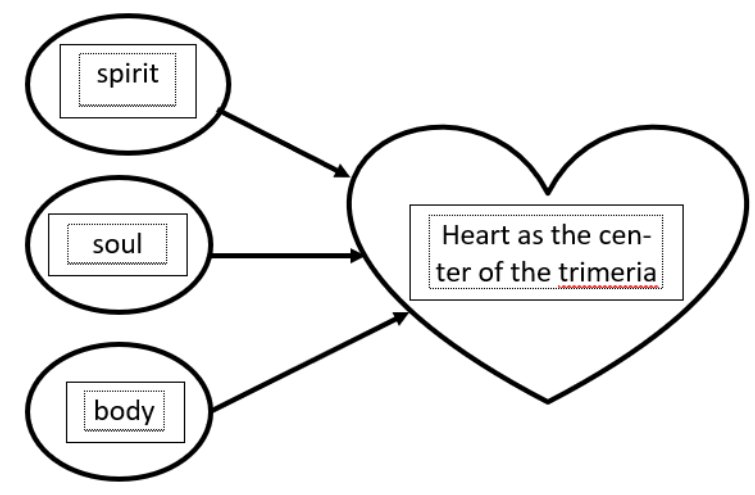

Fig. 1. The heart as a unifying and guiding beginning of human nature.

"The concept of the heart," writes B. P. Vysheslavtsev, "occupies a central place in mysticism, in religion and in the poetry of all peoples" [1]. This explains the enormous difficulties in the study of the problem of the heart, in the development of the philosophy of 
the heart (this term was introduced by B. P. Vysheslavtsev in 1929 in his work "The Heart in Christian and Indian Mysticism"). The fact is that the concept of the heart carries a mystical (religious) meaning, has a universal-universal (philosophical) meaning, a naturalphysiological organ is widely interpreted and studied, also containing a natural biological (scientific) meaning. Therefore, it is very easy to differentiate this concept, to distribute it among different departments - religion, philosophy and science, but it is extremely difficult to superimpose different planes of its study on each other and create a single universalintegrative doctrine of the heart, although these attempts were also made. earlier, take place now, and they are connected within the framework of the development of the philosophy of the heart with the study of the methodological principle of cordiocentrism as the principle of a holistic understanding of the personality and the basis of its connection with society [2].

The concept of the heart was used and discussed in the works of patristic thinkers, Russian and foreign philosophers of the past and present, for example, Theodosius of Pechersky, Sergius of Radonezh, Nil Sorsky, G. S. Skovoroda, A. S. Khomyakov, P. D. Yurkevich, N. K. Roerich, B. P. Vysheslavtsev, A. S. Pozov, V. V. Zenkovsky, Archbishop Luke VoynoYasenetsky, I. A. Ilyin, N. K. Gavryushin, G. Ya. Streltsova, B. Pascal, D. Billington, M. Scheler, M. Buber, etc.

On the philosophy of the heart in the 2000s. in Russia and Ukraine, a number of Ph.D. theses have been defended, among which we will point out the works of L. G. Apenysheva "The concept of the heart in systemic philosophy" (2004) [3], S. A. Kalugina "Ethical and philosophical analysis of the heart phenomenon: on the material of Russian philosophical culture of the second half of the XIX - early XX centuries. " (2008) [4], F. N. Yusupova "Metaphysics of the heart in European and Russian philosophy and culture of the XX century: Comparative Analysis "(2009) [5], A. A. Lebedenko" Philosophy of the Heart in the History of Russian Religious and Philosophical Thought of the XI-XX Centuries" (2010) [6] and others.

\section{Results}

An appeal to classical works on the problem of the heart shows that their authors begin with the Holy Scriptures, with that, in modern parlance, a database that contains fundamental information about the heart. P. D. Yurkevich directly writes that the one who "reads the word of God with due attention, he can easily notice that in all sacred books and in all God-inspired writers, the human heart is considered as the focus of the entire bodily and spiritual life of a person, as the most essential organ and the nearest seat of all forces, directions, movements, desires, feelings and thoughts of a person with all their directions and shades. First of all, we will collect some passages from Scripture, from which it will be seen that this view of the sacred writers on the essence and significance of the human heart in all areas of human life is distinguished by certainty, clarity and all signs of conscious conviction, and then we will compare this biblical teaching with views on this subject that dominate in modern science" [7]. "The heart is considered as the focus of the entire bodily and spiritual life of a person" this moment is extremely important for understanding the role and significance of the heart in human life, it is recorded by almost all writers. B. P. Vysheslavtsev notes that "the heart embraces not only the phenomena of mental, but also physical life. All phenomena of life emanate from it and return to it, affect the heart ..." [1]. Archbishop Luka Voino-Yasenetsky writes: "The heart is spoken about on almost every page of the Bible, and the one who reads it for the first time cannot fail to notice that the heart is given importance not only of the central sense organ, but also of the most important organ of cognition, the organ of thought and the perception of spiritual influences. And more than that, according to Holy Scripture, 
the heart is an organ of communication between a person and God, and therefore, it is an organ of higher knowledge" [8].

Actually, the heart as a focus, as embracing all the phenomena of life, as an organ of communication with God - all this immediately gives grounds to talk about the mysticism of the heart, about its highest purpose in the organization and functioning of human nature. According to E. N. Trubetskoy's definition, "mysticism is the perception or experience of the divine, which is expressed not in the one-sided activity of the mind, but takes possession of the entire being of man" [9]. Thus, in the topological arrangement of the multi-component nature of man, the heart rightfully occupies a dominant position. And if for the mysticalreligious tradition this moment is not subject to any doubt and dispute, then nevertheless there is a need to compare such an understanding of the heart with scientific ideas. Very carefully such a comparison is made by Archbishop Luke Voino-Yasenetsky, other authors who show that scientific research in the field of physiology and psyche of feelings, the brain does not contradict the mystical understanding of the meaning of the heart in human life. The study of the interaction of the mystical and scientific interpretation of the place and role of the heart in human life serves as the basis for the development of pragmatic aspects that are significant not only for human life, but also for the transformation of society. But for this, it is precisely necessary to develop a universal ideological concept of the heart, technologically suitable for practical use.

Of the classical philosophers cited by us, P. D. Yurkevich writes about the difficulties of practical application, emphasizing that "the meaning of the heart in the field of human activity is much more decisive, because we judge differently about human actions depending on whether they are determined by external circumstances. and appropriate considerations, or arise from direct and free movements of the heart. Only the latter, in reality, can we attribute moral merit, while the former have, to a greater or lesser extent, the character of physical actions" [7]. I. A. Ilyin says that humanity "must begin a great, restructuring renewal of the soul and spirit: it must revise the structure of its culturally creative acts, recognize their historically formed inconsistency, fill them up, improve and discover new paths to all the great God-given subjects. This is the only way to get out of the current crisis and start spiritual recovery; this is the only way to stop the modern slide into the abyss and begin the period of rebirth and ascent" [10]. And he offers his own version of solving the problem, considering the ways of folding the higher spiritual organs of a person, the basis of which is the heart's contemplation. He comes to the conclusion that "hearty contemplation is the true essence of every creative relationship between man and man: without it there is neither true friendship, nor true marriage and family, but only pale and deceptive shadows of live communication" [10].

Nevertheless, in the history of philosophy and Orthodox thought, we find, moreover, in not-so-distant times, research on the problem of the heart, which surprisingly is not mentioned in modern works on philosophy and metaphysics of the heart, but without reference to which the development of this extremely important and fundamental problems is extremely depleted. We mean the works of the Russian philosopher and Christian thinker of the first half of the 20th century. A. S. Pozov [11]. In the literature, his work has not been studied thoroughly enough, assessments are sometimes given rather harsh.

In particular, N. K. Gavryushin speaks of some closeness of the views of A. S. Pozov to the views of Fr. Vasily Zenkovsky. At the same time, he notes the non-ordinary style, language, manner of thinking of this philosopher, which is why the latter "gives the impression of a chaotic autodidact, an extravagant eccentric, from time-to-time puzzling with plausible and by no means ordinary intuitive insights" [12]. Indeed, A. S. Pozov abundantly quotes the sayings of the Holy Fathers, and the quotation is sometimes annoying, since behind it the coherence of the presentation is hardly visible. A. S. Pozov makes extensive use of 
materials from the history of philosophy, cites contemporary authors, turns to natural science sources, which testifies to a rather wide informative base of his works and cannot but impress this thinker. "The cross-cutting principle of Pozov's constructions," continues N. K. Gavryushin, "is triadicity, and here it must be said directly that its external attractiveness can in no way serve as a criterion for Christian orthodoxy. According to this principle, as is known, the writings of the Neoplatonists (in their systematicity undoubtedly surpassed the patristic writings), Hegel, etc. were built. Triadism is by no means an indicator of the confession of the Holy Trinity, but at times rather testifies to an arbitrary interpretation of this dogma. But the main thing is the principle itself: once it has been put at the foundation of the system, it constantly demands from the author the introduction of such distinctions in the conceptual apparatus of patristic texts, which can only be defined as a kind of hermeneutic violence and arbitrariness. "System" pulls concepts out of their historical context, creates a conflict between systematism and historicalism" [12]. "For the" Orthodox ", Pozov's anthropology still looks overly systematized and methodical; signs of formal kinship with theosophical syncretism are rooted in the depths of the author's intention, but until attempts to systematize the Orthodox worldview along one axis or another stop, this work will undoubtedly have to be reckoned with" [12].

Indeed, in attempts to build a Christian anthropology and systematize the Orthodox worldview as a whole, as long as they exist and continue, the works of A. S. Pozov will have to be reckoned with. And here one should very carefully weigh the courses of his thought, analyze the argumentation, comprehend intuitive insights. It is for this that a thorough, not superficial acquaintance with his works is necessary, it is necessary to think over and over again the cross-cutting principles of his constructions. In our own article we have mentioned, the principle of trinity is analyzed, the features of its action are demonstrated and objections are raised against the position of N. K. Gavryushin. Here we will turn to a very brief examination of some of the positions that are contained in the book by A. S. Pozov "Foundations of ancient church anthropology" and are devoted to the problem of the heart [13]. All citations are borrowed by us from the same book.

\section{Discussion}

Turning to the consideration of human nature, A. S. Pozov adheres to the concept of trimeria: a person includes spirit, soul and body in his composition. Moreover, each of these elements, in turn, consists of three elements. So, the spirit includes three abilities: mind, will and strength. Spirit is the unity of mind, will and strength. The soul contains a small mind (logicon), desire (epithymy) and feeling (thymos). Finally, the body includes lymph, blood and nervous system. All components of human nature are interconnected, but they do not suppress each other and do not mix. This, according to A. S. Pozov, is the basic systatic law: each part of the trimeria retains its independence and individuality. In catastasis, that is, in the fall of man, this law was violated, the parts and forces of man mixed and continue to mix, suppress and absorb one another. The integrity of a person is deformed, violated and destroyed, the spirit, soul and body begin to act separately and the harmonious existence of a person comes to an end. Since each member of human trimeria is also built according to the principle of trinity, then for the realization of the unity and wholeness of a person, it is necessary that harmony also exists within each of these parts, and their joint functioning is carried out synergistically. Taking into account the foregoing, the concept of a whole person is subject to clarification: a person is integral for whom not only all parts of his trimeria function synergistically, but also there is a hypostatic unity (harmony) within each member 
of the trimeria [13]. Therefore, achieving the harmonious unity of a person and maintaining it is an extremely complex process that requires constant serious work on oneself.

A. S. Pozov asserts: "In the systatic plurality of a person there should be a unifying and guiding principle, there should be a central organ, an organ of unity and integration, which carries out the connection of parts, harmony and hierarchy of forces, correlation of organs and apparatuses; there must be an organ of the trinity of trimeria, of spiritual-mental-bodily unity. According to the teachings of ancient church anthropology, such an organ in a human being is the heart" [13]. The role of the heart as a unifying center is manifested, firstly, in the fact that it acts as the center of each of the members of the human trimeria (the center of the spirit; the center of the soul; the center of bodily functions), and secondly, in the fact that that the heart connects all the members of the three-measure with each other. In other words, the heart is the center of life in all its aspects and manifestations. Macarius the Great says: "The heart is the inner body of the body and the first rational fleshly organ" \{Quot. by: [13]\}.

The heart acts as a bodily center - a regulator of blood circulation; it unites the feelings of a person, which are the responses of a single feeling of the heart; the heart, furthermore, is the regulator and distributor of the vital force in the body. The vital force, according to ancient church anthropology, enters the human body from the cosmos - through breathing and digestion. From the lungs the vital force enters the heart, where it is processed into the specific vital energy of a person, into the vital spirit. Further processing of this energy, carried out with the assistance of the nervous system, leads to its transformation into psychic energy. Outputs of this energy occur through the excitement of a person, as well as through his actions.

The role of the heart is also great as the center of mental life: manifestations of feelings, impulses, emotions, passions, affects. Each feeling of the heart corresponds to a certain movement of the soul. Nicodemus Agiorite writes: "The heart has movements similar to the human constitution, which, like the ebb and flow of the ocean, expand and contract. Responding to the movements of feelings and passions, the heart changes them with its movements. If it was possible to observe the heart, then it would be possible to see that from a pleasant heart it seems to run towards and expand. From the hated object, the heart, contracting, is pushed back. In ra-achievement, the heart leaps, boils in anger, in grief, as it were, falls, beats and trembles with fear" $\{$ Cit. by: [13] $\}$.

The whole life of a person's trimeria is reflected in the heart, finds its response in it and manifests itself in the form of moods, likes and dislikes. It gives a sensual color to the whole heart. It is a resonator of life processes. The business of the heart is to feel everything that concerns the personality. Health and ill health of the body, liveliness, lethargy, strength, fatigue, vigor, everything seen and heard, what has been done and is being done - all this is reflected in the heart and irritates it: pleasant or unpleasant. The last word belongs to the heart: it decides, chooses, senses, attracts, commands, in a word, inclines to something or someone. We say in this case: "My heart does not lie to this," "my heart feels," etc. The inclination of the heart is the most important dominant of the earthly life of a person, in it all the forces applied to the heart by spirit, soul and body converge; truth and lies, good and evil, beauty and ugliness, heredity and upbringing, life experience. The inclination of the heart is different in different persons, it is purely individual.

According to the teachings of ancient church anthropology, the heart is the container of the spirit, the center of a person's spiritual life. Plato already places will in the heart. It also serves as a source of spiritual strength. It is well known from the ancient, Old Testament and other church literature that the heart has a mind (mind) - in this connection, it is said about the mind of the heart, about its participation in the thought process. To understand this feature of the heart, let us recall that there are two minds and two activities of the mind: a large, spiritual mind, whose activity is aimed at contemplating the supersensible, transcendental 
world, and a small, spiritual mind, whose activity is aimed at comprehension of the visible, sensual material world. The activity of a great mind proceeds outside of ideas, concepts and judgments. He is ugly and spontaneous. He acts where all sensuality, imagination and ordinary thinking are silent. This mind is bestele-sen, it does not think, but it contemplates. He perceives objects in their inner ideal essence, sees the hidden spiritual. This contemplative mind is the inner mind of the heart. "If the mind is more or less well oriented in the visible environment, then the same cannot be said about its orientation in the invisible, spiritual environment. This disorientation in the spiritual world that surrounds us, like the visible world, is expressed in diseases of the mind and spirit: in atheism, rationalism, skepticism, criticism, agnosticism, positivism, solipsism, etc." [13]. The duality of the mind is a manifestation of the duality of the nature of man, his spirituality and soulfulness, heavenly and earthly, inner and outer man. The heart does not have organs for external activity, therefore, all its movements are hidden inside a person and are manifested through the head, through various states of the person.

The heart has so-called spiritual feelings, which, starting with Aristotle, include theoretical, practical and aesthetic feelings. The theoretical feelings of the heart are born, according to the teachings of Theophan Tam-Bovskii, from the attitude of the heart to cognizable truths. The main thing here is a sense of truth. These include various degrees of conviction and non-conviction: confidence, doubt, disbelief, bewilderment, and likelihood. A sense of truth means that a person has the ability to comprehend the true order of things with his heart, but this ability manifests itself in different ways in different people. Practical senses are movements of the heart associated with the will. They then excite her, then follow her. These include a sense of self-stness (egoism) and various kinds of disposition towards people, good and evil: respect, regret, appreciation, enmity, envy, hatred, gloating, contempt, etc. Aesthetic feelings are such movements hearts, which arise from the movement of the socalled graceful objects. The heart enjoys the object because it is good in itself, regardless of our interests. The feeling of the graceful is the memory of the lost paradise or the anticipation of the future heavenly kingdom. The content of the graceful is the objects of the spiritual world, which correspond to the corresponding external form.

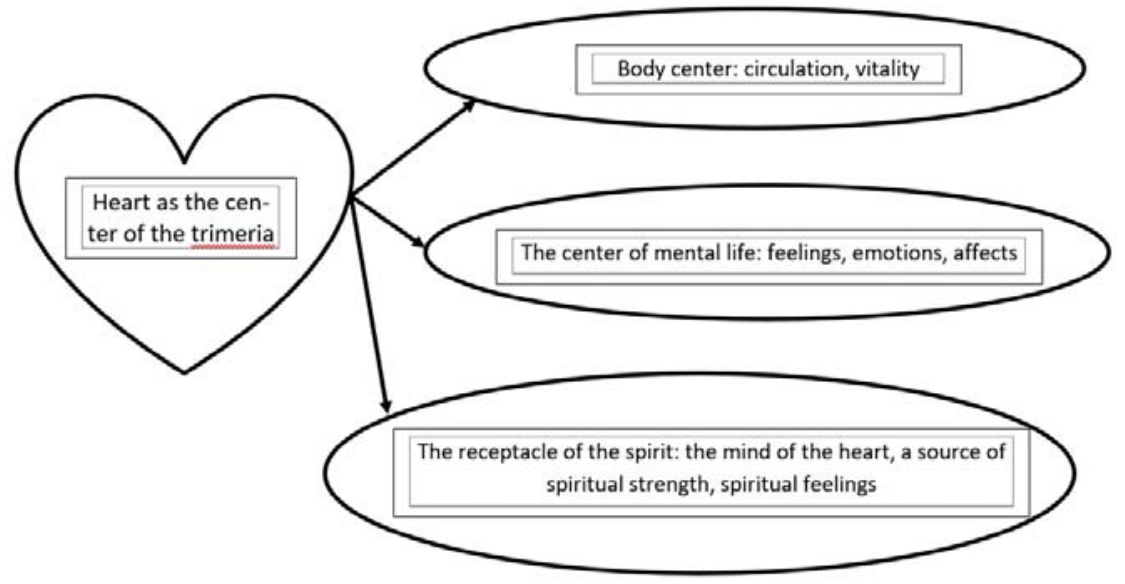

Fig. 2. Heart as a bodily center, center of spiritual life and capacity of the spirit.

The heart is the keeper of all external and internal influences, it concentrates in itself all the experience of life. In the heart is also stored pre-experienced material that has not been 
experienced personally by a person, reflecting the life of mankind. Therefore, the heart possesses memory and from it draws its experience, intuitions, which tell it what to do. The memory of the heart forms the basis of a person's subconsciousness, is the source from which consciousness draws material for creativity, cognition, thinking.

The heart is the organ of human unity and integration. Without it, the parts of the trimeria can only act separately. But this means that without a heart, a person disintegrates. A person lives as an integral, single being as long as his heart is alive and beating. The death of the heart is the death of the whole person. First of all, here we are talking not about the physical, but about the spiritual death of a person, the death of the heart. The heart dies spiritually when the light and fire of the spirit are extinguished in it and the darkness and coldness of the abyss reign.

The heart processes all influences coming to a person - earthly, heavenly, cosmic - reflects and modifies, synthesizes them. This activity of the heart takes place subconsciously, that is, outside the control of the brain and consciousness. But his movements can be made conscious for the head, the efforts of the heart and the brain can be combined. This is one of the tasks of intelligent prayer meditation. Spiritual-mental-bodily health of a person depends on the relationship between subconsciousness and consciousness. A pure and virtuous heart rejects and neutralizes all harmful external influences and protects the entire trimeria of a person. This is the activity of the heart. On the contrary, the passive heart loses the ability to spiritually distinguish between good and evil, truth and falsehood, and opens up to all influences. The passivity of the heart leads to the spiritual death of a person.

Ancient church anthropology says that at the time of his fall, man opened his heart to evil, and since then it has become the abode and instrument of evil. The Gospel says that "from the heart come evil thoughts, murder, adultery, fornication, theft, perjury, blasphemy" [Matt. $15,19]$. The heart became the center of the struggle of forces, the enslavement and suppression of some forces by others. The lower forces suppressed and subdued the higher ones, the spirit became a slave to the flesh. The general coarsening of human trimeria in ancient church anthropology is called stoutness.

A heart that is defeated and persistent in its anti-nature is called unclean. An impure and crafty heart has its own "wisdom of this world", its mysticism and religion, worships its idols, and in its pride deifies itself, rejecting Divine dogmas and Revelation. An evil and unclean heart hardens, it leads to atheism.

Everything that happens in the visible and invisible world is deposited in the heart and stored in it. This repository of life experience in ancient church literature is called the chamber of the heart. In addition, it also speaks about the "bowels of the heart", which mean the deposits of impurities of the heart. In such a heart, according to Neil of Sinai, "thieves and robbers settle down and take whatever they like. An unlocked house turns into a place of filth and stench" $\{$ Quot. by: [13]\}. In this case, the heart becomes the abode of a great parasite that feeds on human passions. It falls into the abyss. The light of the mind is extinguished in the abyss of the heart, the soul is immersed in the darkness of ignorance.

Only Divine light in man can remove the darkness of ignorance and prevent human light from fading away. Only the Divine supernatural, which is simultaneously outside and inside a person, can kindle and maintain such a light. And since this Deity is present in the human heart, to the extent that many ancient church writers speak of the heart as a supernatural center, in which everything superphysical, supersensible and superintelligent, transcendental and heavenly is present. In this case, the heart becomes a place of reign within ourselves, including the Absolute and Relative Being. It takes in Divine grace and becomes the center of the three-dimensionality of man, its master.

The disclosure of the innate and blessed supernatural of the heart is the essence of the ancient church mysticism of the heart. For in the most unclean heart there is always one 
untouched corner, which becomes the center of all mystical experiences leading to restoration, renewal, new birth. Divine light and natural light of mind and spirit meet in the heart, and it becomes a source of wisdom. The heart is the temple of God in man. In the heart, a person comes into contact with infinity, freedom, eternity and immortality. This is the only transcendental organ in man, where the relativity comes into contact with the Absolute, the finite - with the infinite. The heart is the place of realization of the divine Trinity. It contains heaven and hell, the Kingdom and the Abyss, glory and shame, the altar of the temple and a den of corruption, the joy and horror of being; it is the meeting place of God and man, light and darkness, beauty and ugliness, fire and cold, good and evil; a place of contact between animal and divine nature, visible and invisible, renewal and fading, birth and death. And man is called to take part in the battle of good and evil, light and darkness in his heart. Apocatastasis (restoration) in Christianity is carried out in the heart and through the heart of a person.

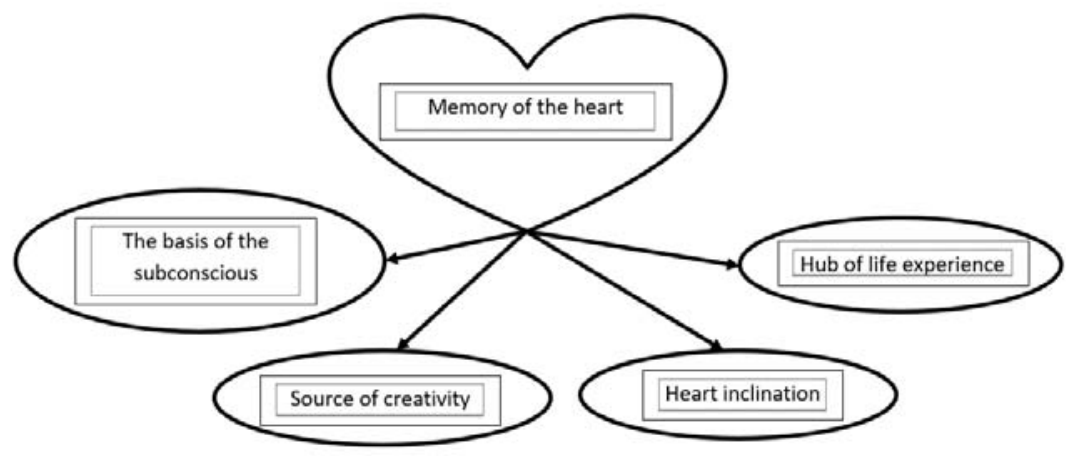

Fig. 3. Heart as a source of wisdom.

Spirit, soul and body, forming human trimeria, are in mutual hierarchy and harmony and are forms of life on three different planes. That which lives and manifests itself in a person simultaneously in all these three planes is at the same time a connecting link of these parts, their central core: this is the human I, personality. Sometimes this I am called the spiritual center of the personality. The wholeness of the I, the hierarchy and harmony of the constituent parts of a person is to a large extent an ideal that requires implementation and, accordingly, the application of efforts. Destruction, and even just a violation of the integrity of the I is the essence of the earthly tragedy of man, which manifests itself in the different fate of the two main parts of man: earthly, carnal and heavenly, spiritual.

Earthly man was created immortal and eternal, but through the fall he put the fate of his body at stake, the spirit gave matter to death. The earthly man dies and disappears, the heavenly man, innocent by nature, remains. The separation of an earthly person from a heavenly person occurs not only in death, but also in life, in particular, during sleep. It is the earthly person who sleeps, and the heavenly one is constantly active, for example, in dreams. It is the earthly person who sleeps, and the heavenly one is constantly active, for example, in dreams. The earthly person lives as if during the day, having numerous needs, which modern culture further increases and diversifies. Generation of new needs, in the long term - the eternal pursuit of them, this is the essence of modern civilization. This is how the cult of consumption is born.

Heavenly man lives a hidden life, at times manifesting his activity in ordinary consciousness, transferring his thoughts, feelings, desires from the subconscious to consciousness. Two lives, as if going in parallel, enter one into the other, and a person is 
surprised to see that within himself he has a different, second life, hidden and imperceptible. This second person is known to all of us as the inner voice, our second self, the inner self. Religious efforts in Christianity have been reduced to making this second, hidden life explicit and effective, because only in it is it visible real bliss and peace.

The duality of human nature found its expression in the ancient Church teaching about the external and internal man. The concept of "inner man" was first encountered by Plato. In ancient church literature, the concept of the inner man is strengthened by the Apostle Paul. Christian "life in the spirit" is possible and realizable only where the inner man reigns supreme. One who has no religious feeling and religious need is in the power of an external person.

The external person indulges in vices, passions, thoughts. This is a spiritually poor, flawed person. And when the external person begins to dominate the internal, the kingdom of evil reigns in the heart of a person and all the forces of its trimeria rush to the worldly. The external person is characterized by: a) the predominance of sensuality, fantasy; b) the aspiration of the soul to the body; c) the rational mind; and d) the spirit, also facing the body. The inner man is made up of: a) the soul turned to the spirit and God; b) a spirit turned to himself and God. This person is strengthened by the supernatural and postal powers of Jesus Christ and the Holy Spirit; he sees with a spiritual and heartfelt eye, while the external person has only sensory vision. There is a confrontation between the external and the internal person: the external seeks to suppress the internal, and the desire for the internal is associated with the limitation of the former. And the path to the Kingdom of Heaven is the path to the inner man, full of thorns and trials. The weakening of the external person leads to a mystic awakening of the internal. The first step towards this, therefore, and towards perfection, consists in "weakening" ties with the outside world in the form of limiting external needs, tempering passions, fighting thoughts, neglecting material goods, the pursuit of material wealth. The Russian philosopher S. L. Frank wrote: "Apparently, the ability to "settle in life", to obtain the benefits of life, to assert and expand one's position in the struggle in life is inversely proportional to the attention paid to the question of the "meaning of life"... And the calmer, the more measured and ordered the outer life, the more it is occupied with current earthly interests and has good luck in their implementation, the deeper the spiritual grave in which the question of the meaning of life is buried" [14] Thus, the question of the meaning of life and, accordingly, its definite solution is "tied" at the intersection (and opposition) of the inner and outer man. Orientation towards affirmation in the life of an external person is tantamount to the death of an internal person, which means that the external person himself dies mentally and spiritually, he becomes a zombie individual, a blind toy in the hands of others.

The path from the external to the internal is the mystical Christian path to salvation. On this path, a person meets all the virtues and is surprised to be convinced that these are his own virtues. He finds in himself a storehouse of endless knowledge, the gift of dispassion and silence, strength and bliss, a pure heart. "If you have purity, dispassion, alienation from evil, then, without a doubt, there is God in you," says one of the greatest ancient church mystics, Gregory of Nyssa. The ideal image of the internal (spiritual) person freed from the slavery of the external is Jesus Christ.

\section{Conclusion}

In conclusion, let us return to the question of the practical implementation (pragmatics) of the doctrine of the heart, to heartfelt contemplation. Reading A. S. Pozov, despite and despite his confusion, it is impossible not to succumb to the charm of his intuitive insights. It seems 
that he sets out not only the foundations of the mystical doctrine of the heart, but also immediately puts it into the language of direct practical implementation, his reasoning is so bright and techno-logical. And at the same time, it is clear that this transition from mysticism to pragmatics has not been worked out at all, that on this path we are faced with enormous difficulties. On the one hand, A. Pozov says that the heart "is a resonator of life processes," that is, everything is not only deposited in the heart, but it reacts to everything that happens, influencing human behavior. But, on the other hand, the heart "does not have organs for external activity" and therefore there is nothing to rely on in the regulation of cardiac activity. "The depth and intimacy of cardiac processes is the reason that these processes are subconscious and therefore inaccessible to scientific research" [13]. Perhaps the most important act of pragmatics is "to transfer into the head consciousness the spiritual and divine aspect of the heart subconscious and draw out the demonic and infernal content of the heart subconscious" [13]. And here we can only formulate - as a kind of immediate program - a series of questions regarding the study of the pragmatics of the heart. First of all, it is the question of the role of the heart in a crisis situation, which we are all experiencing today. Therefore, this is closely related to the problem of the status, role and significance of the heart in a very difficult transformation (as well as mutation of its nature) of a person (along the lines of the body, soul and spirit, integral centralization of this by the heart). In the history of Russia, there was one situation associated with the election of President Boris N. Yeltsin, when the people were addressed through the media with an appeal: "Choose (vote) with your heart!" destinies of their country. This, in our opinion, is related to the question of the evolution of the forms of "heart contemplation" (I. A. Ilyin). Quite pertinent is the question of the limits of cardiac exposure (admissibility / inadmissibility). And finally, the question of the role of the heart in shaping digital reality. A. Pozov asserts: "Intellectual processes, volitional acts, the life of feelings are reflected in the heart. Thought and action must be felt by the heart, and only then they acquire power and significance" [13]. And, we add, only then they will acquire a human, all too human content, which we so lack in building an extremely promising digital civilization.

\section{References}

1. B. P. Vysheslavtsev, Eternal in Russian philosophy. Section X. The meaning of the heart in philosophy and religion // URL: https://azbyka.ru/otechnik/Boris_Vysheslavcev/vechnoe-v-russkoj-filosofii/10

2. S. Kent, Religion, 19, 2, 157-178 (1989), https://doi.org/10.1016/0048721X(89)90038-9

A. A. Lebedenko, Philosophy of the heart in Russian thought and the philosophical system of living ethics // URL: https://gigabaza.ru/doc/91304.html

3. L. G. Apenysheva, The concept of the heart in system philosophy // URL: http://cheloveknauka.com/kontseptsiya-serdtsa-v-sistemnoy-filosofii

4. M. Zandi, Procedia - Social and Behavioral Sciences, 18, 928-931 (2011)

5. S.A. Kalugina, Ethical and philosophical analysis of the phenomenon of the heart: on the material of Russian philosophical culture of the second half of the XIX - early XX centuries // URL: https://www.dissforall.com/_catalog/t12/_science/176/714236.html

6. F.N. Yusupova, Metaphysics of the heart in European and Russian philosophy and culture of the XX century. : comparative analysis // URL:

https://www.dissforall.com/_catalog/t12/_science/182/194174.html 
7. A.A. Lebedenko, Philosophy of the heart in the history of Russian religious and philosophical thought of the XI-XX centuries // URL: http://www.dslib.net/istoriafilosofii/filosofija-serdca-v-istorii-russkoj-religiozno-filosofskoj-mysli-xi-xxvv.html\#4567111

8. A. Kasher, Journal of Pragmatics, 8, 4, 539-557 (1984)

9. P. D. Yurkevich, Heart and its meaning in the spiritual life of a person according to the teachings of the Word of God // URL:

https://azbyka.ru/otechnik/Pamfil_Yurkevich/serdtse-i-ego-znachenie-v-duhovnojzhizni-cheloveka-po-ucheniyu-slova-bozhija/

10. V. F. Voino-Yasenetsky, Spirit, soul, body // URL: https://azbyka.ru/otechnik/Luka_Vojno-Jasenetskij/dukh-dusha-i-telo/\#0_4

11. N. S. Rybakov, Christian thinker Avraam Samuilovich Pozov // URL: https://rudocs.exdat.com/docs/index-266867.html

12. N.K. Gavryushin, Self-knowledge as a sacrament (Preface) // URL: https://azbyka.ru/otechnik/antropologiya-i-asketika/russkaja-religioznajaantropologija-tom-1/\#0_1

13. A.S. Pozov (Posidis), Foundations of ancient church anthropology. T.1. Son of man. Section: Heart // URL: https://azbyka.ru/otechnik/Avraam_Pozov/osnovydrevnetserkovnoj-antropologii-tom-1-syn-chelovecheskij/1

14. S. L. Frank, The Meaning of Life (M. : ACT, 2004), URL: https://azbyka.ru/otechnik/Semen_Frank/smysl-zhizni/1 